\title{
THE COMPOSITION OF FEN PEAT HUMIC SUBSTANCES BY MEANS OF 3D FLUORESCENCE SPECTROSCOPY WITH PARALLEL FACTOR MODELLING
}

\author{
Jānis Krūmiṇš, Māris Kḷaviṇš, Valdis Segliṇš \\ Faculty of Geography and Earth Sciences, University of Latvia, \\ e-mail: krumins.janis@lu.Iv, maris.klavins@lu.lv, valdis.seglins@lu.lv
}

\begin{abstract}
Annotation. The purpose of this study was to conduct a comprehensive structural characterization of fen peat humic substances by means of 3D fluorescence spectroscopy with parallel factor modelling. The fen peat profile $(2.60 \mathrm{~m})$ of Vīksu Bog, with known physico-chemical characteristics, was studied. Fluorescence spectra (EEM) of humic substances were recorded every $0.10 \mathrm{~m}$ of peat profile. EEM reflect significant changes in the decomposition of fen peat and in the formation of fulvic acids (a peak around 350/450 nm), both followed by changes in peat properties and depth. Parallel factor analysis identified a four-component model with well-extracted fingerprint regions, identifying the main constituents of fen peat humic substances: 1) phenolic groups, 2) chromophore groups with high carboxylic group content, 3) proteins and phytochlorin, and 4) polycyclic aromatics with fused benzene rings. Our study has shown that the use of parallel factor analysis on the fluorescence spectra allows processing organic samples with low concentration of humic substances; thereby enabling analysis of very sensitive data that otherwise would be lost during the analysis and lead to the misinterpretation of results.
\end{abstract}

Keywords: fen peat, humic substances, PARAFAC analysis, 3D fluorescence spectroscopy.

\section{Introduction}

Due to the decomposition process organic matter in fens has been transformed into more stable and complex macromolecules than it is in the mire vegetation (Wei et al. 2014). Moreover, the transformation of organic matter into fen peat has the direct impact on element cycle in environment and microbial activities within the peat profile (Cronan et al. 1992). Most of the organic matter in peat is constituted of humic substances (fulvic and humic acids), which basically is the result of degradation and polymerization of organic matter during the microbial, chemical and photochemical reactions (Pernet-Courdier et al. 2011). One of the most advanced and novel methods 
for the determination and characterization of humic substances can be 3D fluorescence spectroscopy. This method can be used as a non-destructive tool to quantify the decomposition degree of organic matter of any kind, and it requires a small volume of aqueous sample at low concentration (Wei et al. 2014). 3D fluorescence spectroscopy provides an important information on the chemical nature of humic substances - on their position, shift and intensity of fluorescence peaks, - and all those data can be correlated to structural information, such as functional groups, polycondensation, aromaticity, heterogeneity and various dynamic properties related to their intramolecular and intermolecular interactions (Chen et al. 2003). All the information obtained from 3D fluorescence spectroscopy analysis can be used in parallel factor analysis (PARAFAC analysis), what is being used to determine the similarity between samples or groups of samples and allows evaluating particular structural components of humic substances. The objective of this study was to conduct a comprehensive structural characterization of fen peat humic substances.

\section{Materials and methods}

26 fen peat samples were extracted from a complete peat profile (every $0.10 \mathrm{~m}$ of a $2.60 \mathrm{~m}$ long peat profile) of Vīku Mire in Western Latvia. The sampling was done in the central part of the mire, which is less affected by the adjacent area and where the most complete geological section can be found. $10 \mathrm{mg}$ of peat powder were extracted with $50 \mathrm{ml}$ of $8 \% \mathrm{NaOH}$ solution for $24 \mathrm{~h}$ in a horizontal shaker at room temperature. The samples were filtered, removing any suspensions, and their $\mathrm{pH}$ was normalized to 7 . Extracts of the samples were further used in 3D fluorescence spectroscopy analysis. 3D fluorescence spectroscopy analysis was performed using a TL spectrometer HORIBA Aqualog. Fluorescence spectra (EEM) were recorded at a $5 \mathrm{~nm}$ bandpass excitation in a clear quartz cuvette. EEMs were obtained by subsequently scanning the emission spectra from 250 to $600 \mathrm{~nm}$ at the 250 to $600 \mathrm{~nm}$ excitation wavelengths with $5 \mathrm{~nm}$ increments. PARAFAC analysis was performed using the MATLAB R2014a v. 5.3.0.532 software with DOMFluor and drEEM toolboxes (Murphy et al. 2013).

\section{Results and discussion}

Features of the fen peat botanical composition in different layers (Figure 1) determine the amount of organic matter in peat (in our study from 60 to 97\%) and cause changes in the rate and intensity of decomposition and thereby also in the amount of humic substances and their fluorescent characteristics relative to peat profile depth.

We have detected 2 general spectral peaks in EEMs of humic substances extracted from studied peat samples (Figure 2). The first peak was centred at the wavelength pair of 330-360/430-530 nm and it is related to fulvic acid-like compounds. The second peak had its own wavelength pair at 430-470/520-560 nm, which is associated with humic acid-like substances (Wei et al. 2014).

All of the recorded humic substance EEMs, as seen, e.g., in samples 5 and 6 (Figure 2); show a higher fluorescence intensity of fulvic acids at the range $\sim 350 / 460$ $\mathrm{nm}$, while the intensity of humic acids $(\sim 70 / 540 \mathrm{~nm})$ is less pronounced. This can be 
explained by the fact that humic acids, being highly condensed structures, have a weaker fluorescence signal than fulvic acids (chromophore groups with high phenolic group content). Further data analysis and validation confirmed that the 4-component model was reliable for studied fen peat humic substances, respectively - fen peat humic substances consist of 4 main components.

Some of the fluorescence fractions cannot be identified from the raw EEM data; it is because of the signal overlap of individual organic compounds. This issue can be fixed with PARAFAC analysis (Zhu et al. 2014). It is for this reason that PARAFAC analysis was selected in our study to distinguish the peat-forming components (Figure 3).

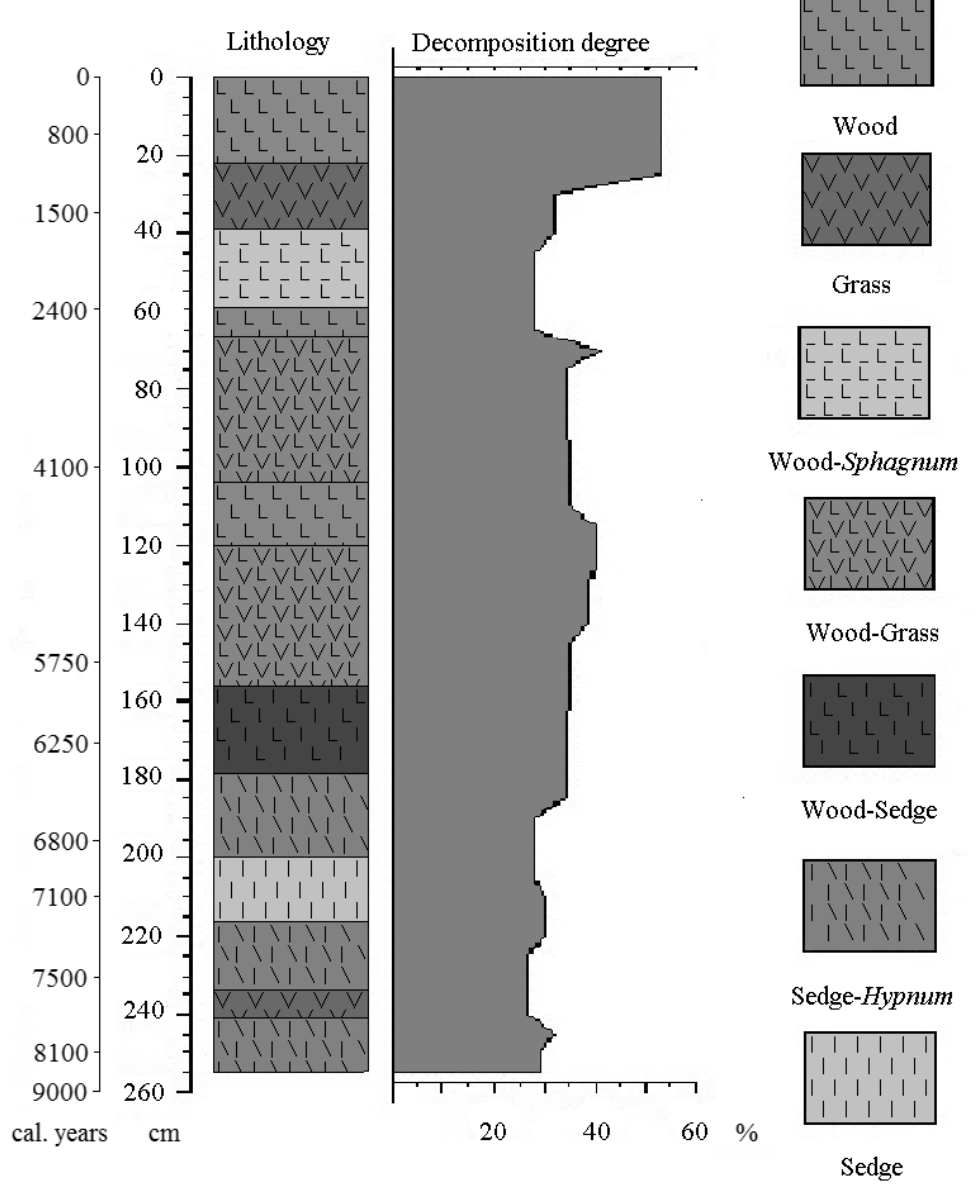

Figure 1. The botanical composition and decomposition degree of Vīḳu Mire fen peat 

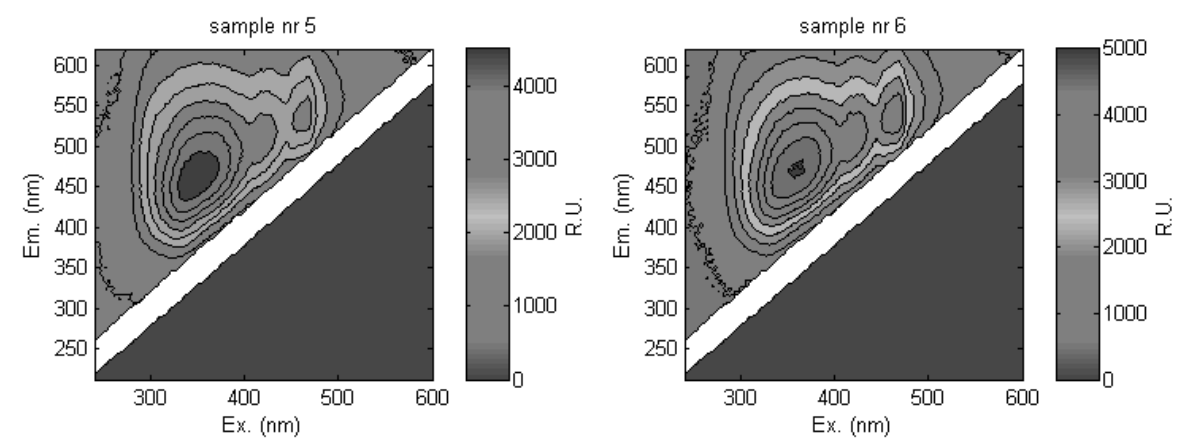

Figure 2. Excitation-emission matrices of Vīḳu Mire fen peat humic substances (0.40$0.60 \mathrm{~m}$ )
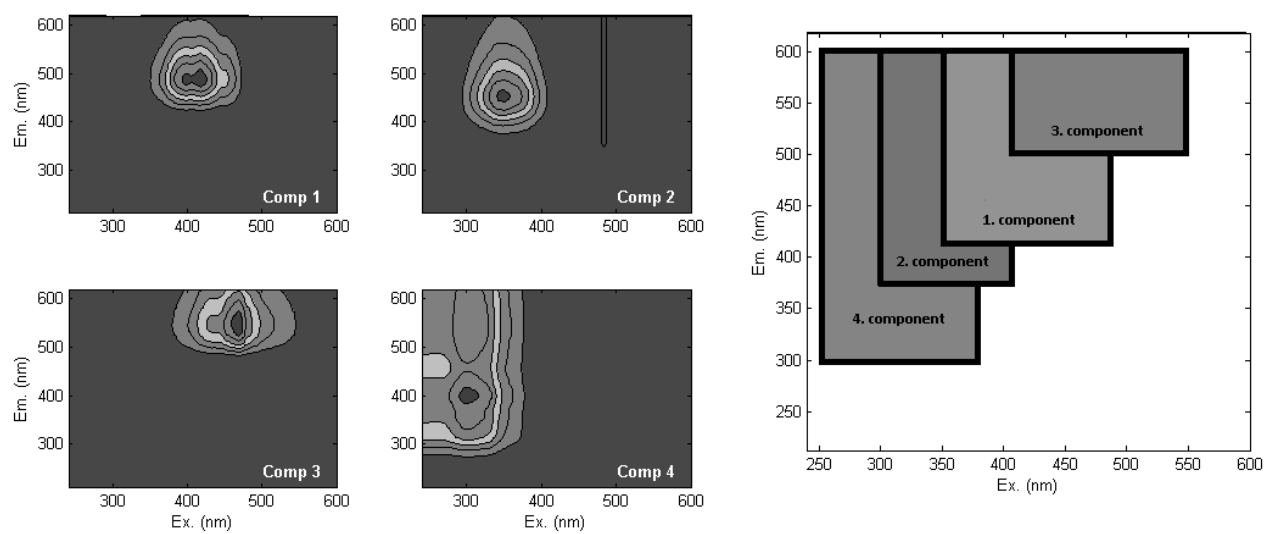

Figure 3. A decomposition of excitation-emission matrix of fen peat humic substances

Figure 3 shows the fluorescence components and illustrates the area on EEM they have the main influence on. There were 4 components found, what were further denoted as Comp. 1, Comp. 2, Comp. 3 and Comp. 4. The fluorescence components were classified according to the previous studies (Stedmon and Bro 2008, Zhu et al. 2014), respectively - component 1 was classified as the phenolic group-containing structures; component 2 was classified as chromophore group with high carboxyl group content; component 3 was composed of proteins and phytochlorin; and component 4 was classified as polycyclic aromatics with fused benzene rings, although it had very weak total luminescence intensity.

\section{Conclusions}

Our study has shown that parallel factor analysis of 3D fluorescence spectra allows processing organic samples with low humic substance concentration. Therefore it is possible to analyze very sensitive data that otherwise can be lost, leading to misinterpretation of results. Our results have also shown that it is possible to apply a 4 component/factor model to the studied fen peat humic substances: $1^{\text {st }}, 2^{\text {nd }}$ and $4^{\text {th }}$ 
component (the phenolic and carboxylic groups, and polycyclic aromatics) and the $3^{\text {rd }}$ component (proteins and phytochlorin), what are main fen peat forming compounds.

\section{Acknowledgements}

Financial support from the National Research Program "ResProd" is acknowledged.

\section{References}

Chen, W., Westerhoff, P., Leenheer, J.A., Booksh, K. (2003). Fluorescence excitationemission matrix regional integration to quantify spectra for dissolved organic matter. Environmental Science Technologies, 37, 5701-5710.

Cronan, C.S., Lakshman, S., Patterson, H.H. (1992). Effects of disturbance and soil amendments on dissolved organic carbon and organic acidity in red pine forest floors. Journal of Environmental Quality, 21, 457-463.

Murphy, K.R., Stedmon, C.A., Graeber, D., Bro, R. (2013). Fluorescence spectroscopy and multi-way techniques. PARAFAC, Analytical Methods, 5, 6557-6566.

Pernet-Coudrier, B., Croue, J.P., Varrault, G., Dignac, M.F., Saad, M., Mouchel, J.M. (2011). Characterization of dissolved organic matter in Parisian urban aquatic systems: predominance of hydrophilic and proteinaceous structures. Biogeochemistry, 106, 89-106.

Stedmon, C.A., Bro, R. (2008). Characterizing dissolved organic matter fluorescence with parallel factor analysis: a tutorial. Limnology and Oceanography: Methods, 6, 572-579.

Wei, Z., Zhao, X., Zhu, C., Xi, B., Zhao, Y., Yu, X. (2014). Assessment of humification degree of dissolved organic matter from different composts using fluorescence spectroscopy technology. Chemosphere, 95, 261-267.

Zhu, G., Yin, J., Zhang, P., Wang, X., Fan, G., Hua, B., Ren, B., Zheng, H., Deng, B. (2014). DOM removal by flocculation process: Fluorescence excitation-emission matrix spectroscopy (EEMs) characterization. Desalination, 346, 38-45.

\section{Summary}

The purpose of this study was to conduct a comprehensive structural characterization of fen peat humic substances by means of 3D fluorescence spectroscopy with parallel factor modelling. The spectra of alkaline extracts reflect significant changes in degradation of peat organic matter and formation of fulvic acids followed by depth and changes in peat properties (a peak around 350/450 nm). Parallel factor analysis allowed the identification of a 4 component model with well-extracted fingerprint regions, identifying phenolic groups, chromophore groups with high carboxylic group content, proteins and phytochlorin and polycyclic aromatics with fused benzene rings. 